\title{
Classroom Discourse of English Language Teachers at Secondary School Level
}

\author{
Soleman Awad Mthkal Alzobidy ${ }^{1} \&$ Afzal Khan ${ }^{2}$ \\ ${ }^{1}$ Department of English Language and Translation, College of Sciences and Theoretical Studies, Saudi Electronic \\ University, Kingdom of Saudi Arabia \\ ${ }^{2}$ Department of English, Alasala University, Kingdom of Saudi Arabia \\ Correspondence: Afzal Khan, Department of English, Alasala University, King Fahad Airport Road, Dammam, \\ Kingdom of Saudi Arabia. E-mail: afzalenghu@gmail.com
}

Received: February 12, 2018 Accepted: November 13, 2018 Online Published: December 29, 2018

doi:10.5539/ijel.v9n1p269 URL: https://doi.org/10.5539/ijel.v9n1p269

\begin{abstract}
This paper compares and analyzes the classroom discourse of English language teachers at secondary level. An English teacher at this level has an enormous responsibility upon his shoulders because he has not only to cover the syllabus in time but also has to develop language skills in his students while preparing the students well for the upcoming board exam. This study makes a comparison of the discourse of two English teachers-one from the private sector and the other from the public sector. The discourse of an English teacher has a direct impact on the performance of his or her students. The present paper provides an initial cursory glance at the result in both sectors.
\end{abstract}

Keywords: classroom discourse analysis, teachers as researchers, teacher awareness, student performance, private and public sector schools

\section{Introduction}

Originally, the word "discourse" comes from the Latin "discursus" which means "to run to and fro". The word "current" comes from the same Latin root - that is discourse which moves back and forth between reflecting and constructing the social world (Wodak \& Meyer, 2009). Within a CDA tradition, discourse has been defined as language in social practice. Discourse means "verbal communication, talk, formal speech or writing on a subject and unit of text used by the linguist for the analysis of linguistic phenomena that range over more than one sentence". Discourse analysis (DA) is a general term for a number of approaches to analyze written, spoken and signed language or any significant semiotic event. The term discourse analysis was first employed by Zelling Harris, when he published a paper entitled "Discourse Analysis". He used this term to designate "a method for the analysis of the connected speech or writing for continuing descriptive linguistics beyond the limit of a single sentence at a time for regulating culture and language" (Harris, 1952). Discourse analysis is the study of how stretches of a language used in communication assume meaning, purpose and unity for their users: the quality of coherence (Johnson \& Johnson, 1998). Discourse analysis was founded as a discipline in 1960. According to Betsy Rhymes, discourse analysis is the study of how language is affected by the context of its use, Talk within the lesson, students' entire lifetime of socialization and the history of the institution of schooling are important in this regard.

Discourse analysis is the examination of language use by the members of a speech community. It involves looking at both language form and language functions and includes the study of both spoken interaction and written text (Demo, 2001).

The current study was conducted in order to analyze the discourse of English teachers to develop awareness among the teachers in general about the critical role that classroom discourse plays in improving teaching skills and student performance as well as their overall development. Teacher discourse analysis is not a very familiar term in our education circles. Teachers follow the traditional method of teaching and are reluctant to try innovative teaching methods. They don't realize what a great impact teacher's discourse has on the teaching and learning environment. 


\subsection{The Need for Classroom Discourse Analysis}

Knowledge of classroom discourse is very important for language teachers. The job of a teacher is not only to impart to learners the information contained in the text but his wider responsibility is multifaceted. The level of the students in the study under consideration is higher secondary level. A teacher teaching at this level will confront many problems. They have to keep in view the social and individual differences of the students, their educational background, the problem of maintaining discipline in the classrooms, the time factor because he is required to cover the syllabus in due time and is responsible for the grade of the students in the board exam. A teacher must be competent to cope with all these pressures. This is particularly true for private sector teachers because for them it is "survival of the fittest" and they have to keep a constant check and balance on their performance. For this purpose, they mostly depend on the feedback provided by the board exam, the results and the verbal feedback provided by the students, their parents, their colleagues and by the school authority. The best way to judge their performance and to identify weak areas is to indulge in a discourse analysis of their own classroom. For this purpose they can video-tape or audio-tape their own lessons. Videotaped recording provides a better insight into their performance as they can also observe the non-verbal-cues, eye-contact, facial expression, gestures, body movements and so on. With regard to the case of public sector teachers, they do not face any threat to their jobs in case of poor performance. They are better paid than private sector teachers. They do not feel themselves responsible to anyone regarding their efficiency. As a result the teachers are least bothered about classrooms discourse analysis. But in the face of changing circumstances, steps are now being taken by the government to properly monitor teacher performance across public sector schools.

\subsection{The Effectiveness of Classrooms Discourse Analysis}

At present we live in world that has become a 'global village'. The developing nations of the world give primary importance to their education and teaching methodology in order to best achieve the goals they have set for themselves. Myriad research has been done on teacher discourse and teachers play a pivotal role in bringing about positive change in society by shaping the future of their nations in the form of their students who are well-equipped for their practical life. The analysis of classroom discourse provides teachers with an opportunity to monitor their performance, to notice their weak areas, to know the problems which students face during their lessons but which they cannot give voice to owing to reticence, shortage of time or some other factor. Having recorded their own lessons, the teachers are in the best position to compare their classroom performance with their fellow teachers and to improve upon it. Classroom discourse does not involve the use of language for mere communication. Apart from the linguistic function, it serves a social function as well. Classroom discourse has many dimensions and only that teacher can compete with international standards who can execute this tool well. The way the teacher allows his students to participate in different learning activities plays a key role in the overall growth of the learner. The discourse of the teacher has certain moral implications.

\subsection{Cultural Differences}

The influence of increasing cultural variations on students' classroom education has been a challenging concern for scholars at least for the last 30 years (Cazden, 2003). Schoolrooms are the places that increase intercultural contact among students particularly in younger grades. Classroom environment provide students with initial extensive experience with a different culture. There is acknowledged discrepancy in discourse patterns across cultures. Producing a hybrid classroom discourse can help in creating more conducive classroom environment.

Applebee, Langer, Nystrand \& Gamoran (2003) analyses report that great academic standards and classroom discourse practices were considerably interconnected to mainspring performance, controlling initial classroom schooling, socio-economic status, gender and race/ethnicity. Likewise, keeping in view the lack of communications between these measures across all grade level in classroom discourse, with equally important is location of the school (urban or rural), maintenance of students record to display their academic ability and qualification of the instructor indicate that these approaches effect a range of situations in classroom discourse. The findings reveal that Asian American students in one ethnic respond even more effectively than the response of their peers in both high academic demands as well as discussion-based approaches.

The present research tends to gauge a teacher's strength in using classroom discourse as an effective tool at higher secondary level in Shams Aljazeera (private school) and Government Secondary School (public school) in Saudi Arabia. The study examines if our English teachers are conscious of the growing demands of English language classroom discourse and if not what steps can be taken in this regard. The current study addresses the following research questions:

1) What can we learn from a comparative analysis of the classroom discourse of English language teachers in private and public sector at higher secondary level? 
2) Do the English language teachers analyze their own classroom discourse and if not then what are the reasons for this?

3) What is the anticipated impact of teacher's discourse analysis on the learning and overall development of learners in both private and public sectors?

\section{Methodology}

In order to find the answers to the above cited questions a research project was undertaken. After receiving prior permission, observation was conducted in an actual classroom situation for a (40) minute lesson of English in the $12^{\text {th }}$ grade class of two schools - one from the private sector and one from public sectors. The following section describes the observation method and the sample selected.

The sampling was non-random. As a matter of convenience that was purely non-experimental, descriptive research. Both the teachers selected were competent with respect to language proficiency. One teacher belongs to The City School and other to the Government Higher Secondary School. The reason for selecting one school from each was that the curriculum is the same and students from both areas and both private and public sectors are tested by the same board (Saudi certificate). Competent teachers were selected in order to check the extent to which they are conscious about the classroom discourse. This will tell us whether or not they are producing learners who can compete with international standards.

\subsection{Instrumentation}

Class observation and interview were the instruments used for this research. The interview followed the classroom observation. The interview lasted not more than 15 minutes. The points for observation were mostly taken from the following two books:

1) Classroom discourse analysis: Tool for critical reflection (Rymes, 2015).

2) Exploring classroom discourse.

The interviews consisted of two open-ended questions. These interview questions are presented in the appendix.

The authorities of the school which were selected for observation were contacted and permission was sought to observe the English language class of the $12^{\text {th }}$ graders for one lesson which comprised of 40 minutes in both schools. After the dismissal of the respective classes, an interview was conducted which lasted for almost 15 minutes.

\section{Findings}

Research question: 1

What can we learn from a comparative analysis of the classroom discourse of English language teachers in private and public sector at higher secondary level?

The private school teacher was well-dressed man of 48 years of age whom we henceforth assign the name Mr. A, while public school teacher was a young man of 33 years of age who will be henceforth called as Mr. B. Mr. B had 15 years teaching experience in total: 10 years' experience in the private sector in addition to spending the past five years serving in the public sector. Both the teachers were requested to teach the same lesson from the textbook of English for12th graders. The name of lesson that was taught was Communication.

Class conducted by Mr. A

I entered the class with Mr. A. The door of the class was towards the back of learners. The white board was fixed toward the front of the class. No charts were displayed in the classroom at all. The bulletin board had two or three articles of graffiti hanging loosely. A dais was perched on a raised platform about two steps higher than the rest of the class. No chair was provided for the teacher to sit on. It was a class of 40 students who were setting in rows of 4 chairs on either side of the space left for walking. The students had no difficulty in seeing the whiteboard or the teacher. The moment the teacher entered the classroom the boys were standing and busy with different activities and the teacher had to raise the volume to ask the student to settle down. In the mess no proper greetings were exchanged between the teacher and students. The teacher then went to the dais and I perched on one of the chairs in the back of the class. The students noticed my presence as they nudged each other but did not greet me either out of reticence or lack of etiquette.

Mr. A was holding a board marker in his hands. He wrote the word "Communication" on the board and started reading the text from the book he had brought along with him. He appeared very competent as for as his linguistic ability, word choice and pronunciation were concerned. He spoke in a clear, loud voice with a good intonation. He made use of the discourse markers (words like "however", "although" and "nevertheless"), transition markers 
(right, ok, now, so, alright) but the teacher held the floor (the right to speak) for almost all the time. At times the students nodded in response when the teacher paused to check their comprehension. There was no eagerness on the part of the students to take a turn and the teacher also seemed unwilling to yield the floor.

Mr. A used grammar translation method. No doubt, he had a good command of English but he translated the text into Arabic, which was done, according to him, to get the students to better understand the text. He provided the synonyms of difficult words in English as well. Code-switching was done. He made his lecture more engaging by interjecting chunks of humor at intervals. Sometimes, he cited examples from real-life situations related to his lesson.

He maintained only enough discipline to ensure that the students remained seated during his presence in the classroom. But he did not mind such things as if students were chewing bubble gum in the classroom and some students sitting at back were working on subjects other than English. Mr. A told me during the interview that they take care of things so that slow learners should be seated with the bright ones. What I noticed was that some students sitting in the front occasionally provided one or two word response. The back benchers however never tried to respond. There was no group work in the class.

Surprisingly, no questions were asked on the part of the teacher or students. So the teacher completed his lecture in a pre-determined, manner without confronting any unexpected or challenging question from the learners. The teacher kept standing behind the rostrum, not roving the classroom. During the course of lecturing the teacher wrote one or two words on the white board and again settled in the former position. He did not make use of A.V aids at all which according to Mr. A was unnecessary as he had an excellent grasp of the subject which he attributed to his hard work and his love of teaching. His love for teaching and learning was evident in his manner as he delivered his lecture with full zeal and zest. But he still clung to the traditional methods of teaching which is paradoxical.

The approach of Mr. A was student-centered and the students were passive learners. He was authoritative, reprimanding the students to pay attention. According to him social differences did not matter in his class because he did not let students bring such things into the classroom. Another reason might be that almost all the students in that school were from well-off families.

Mr. A completed the lesson within the time of one lesson. Students are not provided with any opportunity to do the reading. As a result, there is no chance to correct the learners' pronunciation mistakes. Tests and exams are the only source of providing feedback to both the teacher and the students.

Finally Mr. A tells the students to exercise on their own by verbally giving some cues on how to do this. He dismissed the class by formally assigning the homework. Both the teacher and students say good-bye and the class is dismissed.

\section{Class Conducted By Mr. B}

I entered the class with Mr. B. The door of the class was toward the front. A blackboard was fixed on the front wall. Chalks were neatly placed on the blackboard. A teacher's desk and a chair were placed right in front of the middle row of students. It was a class of 25 students who were divided into three parts. Each row consisted of a desk and a bench which could accommodate three students if required. But as there were only 25 students in the class, only two students sat on each desk and bench set.

The walls were decorated with beautiful charts prepared by the students and displayed neatly. Students had no problem in watching the teacher or blackboard. When we entered the classroom the students were seated with a few exceptions and their books were already open in front of them. They stood up and greeted both of us. The teacher and I responded and Mr. B asked them to sit again. They went to the desk and sat on the chair and I went to the back benches and perched on one of them. Mr. B started reading the chapter "Communication" but before this he wrote the name of the chapter on blackboard and asked few questions to brainstorm the students. Surprisingly enough, the students had done the pre-reading and they had made use of dictionary at home as the meanings were written in their books and the paragraphs were numbered. Mr. B took the round of the class to check whether the students had done the pre-reading or not.

Mr. B also translated the text into Arabic like Mr. A but during reading and translation remained seated. Mr. B had a good command of the language. Although the linguistic markers and the discourse markers were used, he also made use of black channels ("yes", "right", etc.) to check the comprehension of the students. The teacher tried to involve the students by asking a few questions but the students had considerable difficulty in responding in English They either remained silent or responded in Arabic. Mr. B had a loud clear voice with proper pitch and intonation. He made use of facial expressions, gestures and eye-contact. However, most of the speaking time was taken up by 
the teacher and on the whole his method was also traditional as he did not make use of any audio visual aids. The teacher tried to involve the students but some of the students spoke more than the others. Mr. B tried to involve the students by calling them through their names and asked short questions but some of the students seemed introverted and reluctant to respond. Mr. B did not prolong the waiting time as he was in a hurry to complete the chapter within the time limit of one lesson.

MR. B told us that in order to provide all the students with a chance to sit in a front of the class he gets the students to change their seats on weekly basis. We received another surprise when at the end of chapter Mr. B asked the students to read out a few lines from the chapter one by one. Only a few students could read out fluently while the majority faced problems with pronunciation which were corrected by the teacher on the spot. Mr. B tried to give individual attention to all the students keeping in view their individual differences. He left his chair after completing the chapter and went to the seats of the students to help them with their problems but according to Mr. $\mathrm{B}$ he could not do it to a desirable extent because of time constraints.

In response to a question regarding social difference Mr. B responded that most of the students belonged to a particular social background and there was discrimination on the basis of caste systems which he tried to diminish by counseling the students.

When students did complete the reading, Mr. B assigned some questions from the exercise as homework and guided the students in detail on how to undertake them. The seated fellows seemed to help each other with the problems but activities were not designed by the teacher other than those present in the text book. As a result group work was not to be seen.

The teacher dismissed the class with the final reminder to the students to complete the assigned homework and revise the chapter once again at home. Then both the teacher and students exchange thanks with each other and we came out of the classroom.

Research question: 2

Do the English language teachers analyze their classroom discourse and if not why?

The observation of both private and public classrooms and the interview revealed that both Mr. A and Mr. B did not conduct analysis of their classroom discourse. Mr. A knew the process to some extent but he stated during the interview that he did not feel the need to do any such analysis because he was confident enough that his teaching was of a high quality and his students were position holders and showed stellar performance in board exam.

Mr. B did not seem to have much awareness of the process at first. But when I explained the term to him, he was reluctant to use it for lack of resources and time.

From the discussion I had with Mr. A and Mr. B during the course of interview revealed that Mr. A did not feel the need to do analysis of classroom discourse because he can get feedback through tests and exam results and was satisfied with that. He did not seem to be convinced that this analysis also provides the teacher with an opportunity to improve upon his performance.

Mr. B said that public sector schools cannot provide their teacher's facilities to video tape their classroom proceedings. Besides this there are some social limitations to it.

Research question: 3

What is the anticipated impact of teacher's discourse analysis on the learning and overall development of the learners in both private and public sector?

'Those of us who presume to "teach" must not imagine that we know how each student begins to learn' (Paley, 1991).

It is clear from these lines that being a teacher does not alone suffice to know how a student learns and how a teacher can improve his teaching. For this purpose a teacher needs training, dedication and analysis of his own teaching methodology and the best thing for this is classroom discourse. But if these students are to compare or compete with other boards in Saudi Arabia, will they be able to show the similar results? The world is fast progressing in the field of education as in other fields. If our student seeks to go abroad for higher education, will they have enough talent to compete with under international standards? So, why not train them in such a way that they may be well-equipped to compete with any standard right from the beginning.

Mr. B talked about the limited resources and time constraints. Private sector students are resourceful and they can make up for their deficiencies with resources from outside the classroom. But for public sector students, the teacher is the only source from which they can benefit. So the public sector teacher should also be alive to the 
changing demands of the teaching profession. The public sector teacher is well paid as compared to the private sector teacher so it is advisable that he should spend a fraction of it on his professional grooming.

There is lack of awareness regarding classroom discourse analysis within education circles. Workshops and symposia need to be conducted to grow awareness. Exchange visits of our teachers and students with foreign teachers and students, who excel far beyond us in the field of education, will be a very healthy step.

Our teachers need to compare themselves with international standards to enable our posterity to keep pace with the developed nations of the world. Our students have the talent; the only shortcoming is on the parts of teachers that they do not know how to exploit this talent in the best possible way.

The classroom discourse of teachers not only leads to the academic achievement of the learners but improve their personalities as well. Group work trains them to live peacefully and in harmony with other human beings in their community and teaches them collaborative work, which is the key to the success of any nation. If the teachers' attitude is positive towards the students that same positivity will be inculcated in his students. In short, if teachers do the discourse analysis of their own classroom it will bring a positive and revolutionary change in the outcomes of the learning and overall development of our students.

\section{Discussion}

The results revealed by the research instruments used in this study-observation and open-ended questionnaire give us some insight into the existing situation in our education system at higher secondary level. Mr. A and Mr. B are both competent teachers of their respective schools. Both resist the use of classroom discourse analysis, both have a good command on language but both resort to traditional methods of teaching. Their classrooms are teachercentered. They take about $2 / 3$ of the speaking time in the classroom. Both are authoritative. Those common features highlight some of the flaws that are present in our education system irrespective of the discrimination of private and public sector. Teacher training programs should be organized while keeping in view these weak areas.

Some of our observations challenge the established beliefs. Private sector teachers are considered to be more competent and so they have to be if they have got to survive in their system but Mr. A did not believe in preparing the lesson in advance. He did not give personal attention to his students. In spites of all these factors his students produce excellent results. The reasons are the students in such private schools come from well-off families. Only those students can survive in these schools who receive constant support and coaching from their families. The negative side of this is that lack of attention on the part of the teacher gives birth to a tuition culture which is an unnecessary burden on parents and consumes the precious time of student which they could spend in other activities such as games and learning some practical skills which can be beneficial to them in their practical life.

In the private sector little attention is paid to the personal grooming and inculcation of good habits especially obedience in the students. Rudeness and arrogance in the students is often mistaken for confidence. They suffer from a sense of superiority. Here we grow unmindful of the reality that all high and low have to live in the same society and if we do not teach them to endure each other the result is the widespread restlessness in the society.

Mr. B is a public sector teacher who is usually considered to be incompetent, lousy and sluggish. But our observation and interview presents a very different picture. Mr. B was in no way less competent than Mr. A. The causes of this are the positive steps that the government is taking in hiring young, energetic people who are highly qualified as well. The student in the public sector receives the teacher's attention and affection. Consequently, they grow to become balanced personalities though less successful in practical lives. Teachers like Mr. B are very well paid. Their poor results do not cause a threat to their jobs so they do not like to exploit their talent to its fullest. For this the government should devise a strict monitoring system.

\section{Conclusion}

In short, if we want to live in this world as a dignified and successful nation, we shall have to give prime importance to our education system and teachers have got a great responsibility on their shoulders in this regard. The dilemma is that in our country the incompetent people join the education department. Those people should be encouraged to join this profession who are dedicated to save their nation and whose sole interest should not be to make a living out of it.

More qualitative research needs to be conducted on classroom discourse. Until now the bulk of quantitative researches have been conducted on narrow areas of classroom discourse that largely examine comprehension in narrative texts under extremely controlled settings. In this regard it has to capture the full range of classroom discourse processes in order to explain further factors of human processes. The important factors to be considered are: comprehension and interpretation, Individual variations that influence classroom discourse processing, for example syntactic patterns, working memory, meaning, and interpretation of classroom discourse. 


\section{References}

Applebee, A. N., Langer, J. A., Nystrand, M., \& Gamoran, A. (2003). Discussion-based approaches to developing understanding: Classroom instruction and student performance in middle and high school English. American Educational Research Journal, 40(3), 685-730. https://doi.org/10.3102/00028312040003685

Cazden, C. B. (2003). Classroom Discourse. In C. B. Cazden \& S. W. Beck (Eds.), Handbook of discourse processes (pp. 170-202). Routledge.

Demo, D. A. (2001). Discourse Analysis for Language Teachers. ERIC Digest.

Harris, Z. S. (1952). Discourse Analysis: A sample text. Language, 28(4), 1. https://doi.org/10.2307/409987

Johnson, K., \& Johnson, H. (Eds.). (1998). Encyclopedic dictionary of applied linguistics. Blackwell Publishing.

Paley, V. G. (1991). The boy who would be a helicopter. Harvard University Press.

Rymes, B. (2015). Classroom discourse analysis: A tool for critical reflection. Routledge. https://doi.org/10.4324/9781315775630

Wodak, R., \& Meyer, M. (Eds.). (2009). Methods for critical discourse analysis. Sage.

\section{Appendix A}

\section{Open Ended Questionnaire}

1. Do you plan the lesson in advance?

2. Why do you think is it essential to plan the lesson in advance?

3. Should lesson only be text-based?

4. Is student achievement "bottom line" in private institutions?

5. Is student achievement "bottom line" in public institutions?

6. How do you influence learning environment?

7. How do you handle a problem child?

8. Do you try to cut through the preconceptions which lead to certain label to certain students?

9. How do you handle individual and social difference of students?

10. To what extent do you exercise your influence power?

11. To what extent are you positive to students?

12. Do you pick up on stories that students were not allowed to tell during official lesson time?

13. How do you keep your students focused?

14. How do you elicit response from students?

15. How do you face silence?

16. Why should a teacher do classroom discourse analysis?

17. How does sharing of classroom discourse analysis with other teachers help you improve teaching and learning?

18. How can teacher bring lasting positive change in education system?

\section{Appendix B}

\section{Class Observation}

1. Class arrangement

2. Teacher's attire and demeanor.

3. Settling the class.

4. Opening the greetings.

5. Command on English language.

6. Teaching methodology. 
7. Student participation.

8. Student-centered class or teacher-centered.

9. Turn taking

10. Class control

11. Individual differences

12. Social differences

13. Use of linguistics markers

14. Use of discourse markers

15. Elicitation technique

16. Reading and error-correction

17. Nonverbal-cues

18. Use of A.V aids

19. Interaction with students

20. Group work or individual work

21. Teacher authoritative or authoritarian

22. Strategic teaching

23. Class dismissal

\section{Copyrights}

Copyright for this article is retained by the author, with first publication rights granted to the journal.

This is an open-access article distributed under the terms and conditions of the Creative Commons Attribution license (http://creativecommons.org/licenses/by/4.0/). 